\title{
Pharmacy Practice Scenario and Job Satisfaction among Nepalese Pharmacists
}

\author{
*Dharma Prasad Khanal ${ }^{1}$, Bishwo Raj Dhungana ${ }^{2}$, Naresh Kadyat ${ }^{3}$ \\ ${ }^{1,2}$ Manmohan Memorial Institute of Health Sciences, Soalteemode, Kathmandu, Nepal \\ ${ }^{3}$ PRIME Pharmaceuticals Pvt Ltd, Birjung, Nepal
}

*Corresponding Author:

\section{Prof. Dr. Dharma Prasad Khanal; M Pharm PhD}

Email: drdpk@mmihs.edu.np

\section{ABSTRACT}

Introduction: Pharmacists are the key players of the health care system. Job satisfaction is a very important contributing factor for person's productivity and motivation. The main objective of this study is to find out the present scenario of pharmacy practice and job satisfaction of Nepalese pharmacists.

Methods: A practice scenario and job satisfaction related questionnaires were developed and pilot test was done with ten pharmacy practitioners who were practicing from more than ten years in Nepal for reliability. Minor modification on questionnaires was done after pilot testing. Ethical clearance was taken from the MMIHS -IRC.

Results: Male pharmacists are dominating to female. The satisfaction level of Nepalese pharmacist was found to be $73.60 \%$. Similarly, around $73.10 \%$ of pharmacists were satisfied with nature of work and $71.60 \%$ of pharmacists were satisfied with the time duration of work whereas nearly half of the pharmacists were unsatisfied with their income and pay scale.

Conclusion: About 70\% pharmacists are highly productive stage of between ages 20-30 years. The inherent interest in the pharmacy profession found among Nepalese pharmacists is an optimistic and policy-makers could develop, modifying national health policy for the implementation of pharmaceutical service as an integral part of national health care system of the country for the benefit of the public health as a whole.

Keywords: Pharmacist, satisfaction, job, salary, pharmacy practice.

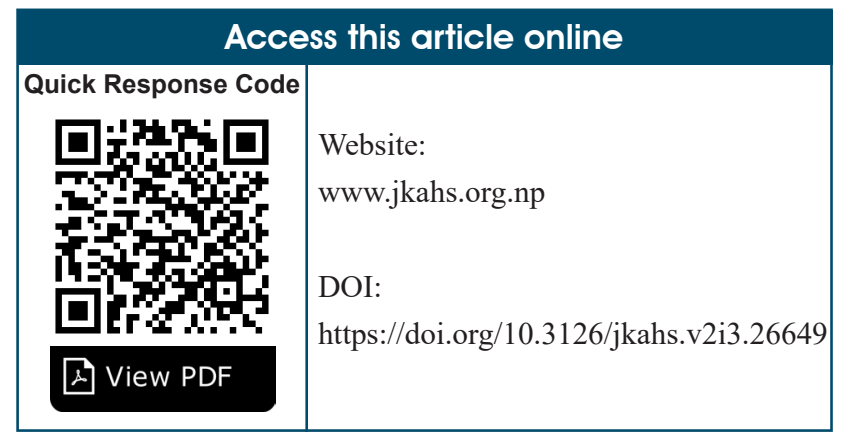

INTRODUCTION

According to FIP1there are 4.067718 licensed pharmacists working in the 74 countries around the globe of which 2,824,984 are actively practicing. In total $75 \%$ pharmacists are working in community setting, $13.30 \%$ in hospitals and $12.7 \%$ in other

\begin{tabular}{|l|}
\multicolumn{1}{|c|}{ Article Info. } \\
\hline How to cite this article? \\
\hline $\begin{array}{l}\text { Khanal DP, Dhungana BR, Kadyat N. Pharmacy Practice Scenario } \\
\text { and Job Satisfaction among Nepalese Pharmacists. Journal of } \\
\text { Karnali Academy of Health Sciences. 2019;2(3): 181-188. }\end{array}$ \\
\hline Received: 17 Oct., Accepted: 29 Nov., Published: 11 Dec. 2019 \\
\hline Conflict of Interest: None, Source of Support: None \\
\hline
\end{tabular}

areas. Pharmacist density per 10,000 population varies countries to countries and lowest 0.04 in Chad to 18.88 in Malta. Several countries have many times more pharmacies than pharmacists (Uruguay, Vietnam, Pakistan, Nepal, Rwanda), flagging the 
issue of appropriate supervision of pharmaceutical services. The female pharmacists varies from lower $20 \%$ to higher $80 \%$ around the countries of the world. Almost $80 \%$ of the pharmacist workforce is female in the Czech Republic whilst only $20 \%$ of the workforce is female in Uganda $^{2}$. Job satisfaction is a very important contributing factor for person's productivity and motivation ${ }^{3}$. Job satisfaction is the extent that a person receives fulfillment or gratification from his/ her workplace activities, the attitude toward the job as a whole. ${ }^{4}$

Job satisfaction is a critical element of any work environment. Thus various studies have been conducted on job satisfaction. Researchers have point out that job satisfaction grading and measurement can be a complex task as it may not be a simple average of workers' satisfaction in different aspect of a job ${ }^{3}$. A theory was proposed by Maslow and his theory guide to assess the hierarchy of needs. His theory proposed a five-tier model of human needs, often represents as hierarchical levels within a pyramid ${ }^{5}$.

The different levels of needs on Maslow's hierarchy are discussed as follows ${ }^{4,5}$ :

(i) Physiological needs: These are biological needs that a person eat, breath and maintain normal physiology, if a person were deprived of all needs, first he/she search for satisfaction of these needs.

(ii) After fulfilling the first physiological need than security needs become active.

(iii) When first two need are satisfied, the third is the needs for love, affection and belongingness can emerge. Maslow clearly described that people attempt to defeat feelings of remote isolation and sadness.

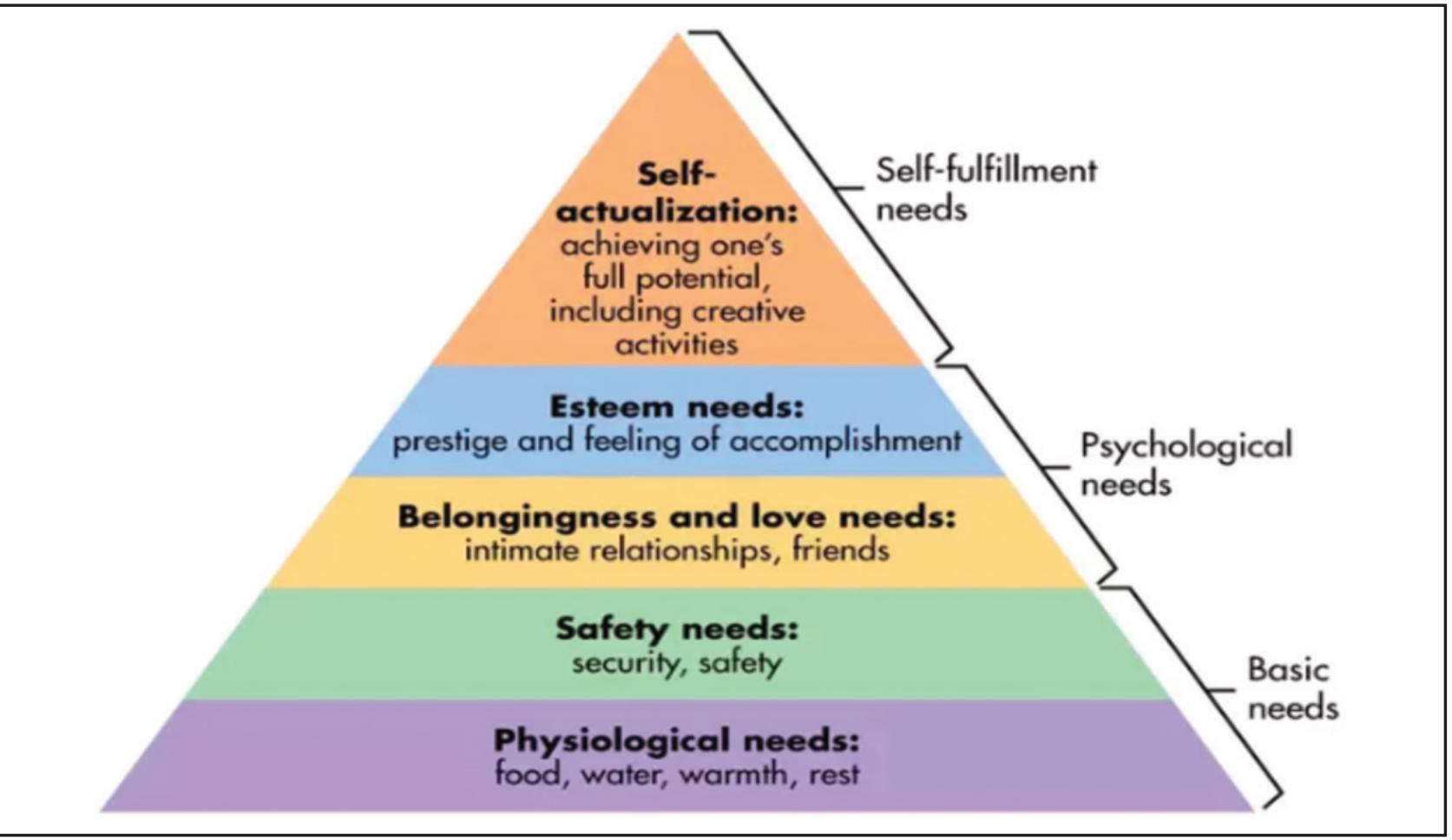

Figure 1: Maslow's hierarchy of needs pyramid ${ }^{6}$

(iv) The forth level is needs for esteem: after the satisfactions of first three level of needs, the needs for esteem can become dominant. This includes self-esteem as well as honor from others. When these needs are not fulfilled, person may be depressed, frustrated, the person feels inferior, weak, helpless and worthless.
When these needs are satisfied, the person feels self-confident and valuable as a person in the world.

(v) Needs for self-actualization: When the satisfaction is achieved up to four level, then and only then are the needs for self-actualization activated. Maslow describes self-actualization 
as a person's need to be and do that which the person was "born to do." "A musician must make music, an artist must paint, and a poet must write." These needs make themselves felt in signs of restlessness.

Similarly, other researchers has also raised the issue of inadequacy of single-item overall job satisfaction measures compared with a composite measure of overall job satisfaction using several job facets?

A pharmacist means a person who has obtained minimum bachelor's degree or the qualification equivalent to that from the recognized educational institution on the pharmacy subject. There are a total of four universities; Tribhuvan University, Kathmandu University, Pokhara University and Purbanchal University. There are 22 B Pharm degree colleges. The pharmacy education and profession in Nepal is regu $\neg$ lated by the Nepal Pharmacy Council 2000 A.D. The pharmaceutical education was started in Nepal with the commencement of the Proficiency Certificate Level, a two and half year program (Intermediate in Pharmacy that is similar to Diploma of Pharmacy) at the Institute of Medicine, Tribhuvan University in 1972 with the leadership of a British Pharmacist Paul David Spivey. But Bachelor of Pharmacy could not be started in institute of Medicine. The Bachelor of pharmacy (B. Pharm) program was started in Kathmandu University in 1994 after twenty two years of PCL program, in Nepal. The B. Pharm programs later were started at Tribhuvan University in 2000, at Pokhara University in 2001 and at Purbanchal University affiliated Asian college in $2007^{8}$. According to Nepal Pharmacy Council [9] currently, 57 educational institutions are running pharmacy courses like diploma in pharmacy (3 year community and hospital based program), bachelor of pharmacy (4 years), master of pharmacy ( 2 years) and doctor of pharmacy are run by different universities. The total number of registered bachelor degree holder pharmacists is 3761 by $2075 / 2076^{9}$.

This implies the ratio of pharmacist to patient ratio is too little, which reveals shortage of pharmacists in Nepal, moreover assistant pharmacists are providing services in many sectors where pharmacists are not available.

\section{MATERIALS AND METHODS}

A set of questionnaires related to personal information a, practice site and job satisfaction were developed and pilot test was done with ten pharmacy practitioners who were practicing from more than ten years in Nepal for reliability. Minor modification on questionnaires was done after pilot testing.

\section{Sample Size:}

Sample size: $\mathrm{d}=2 \sqrt{\mathrm{pq}} / \mathrm{n}$

Where, $n=$ sample size

$\mathrm{p}=$ Probability of pharmacist with satisfaction $=50 \%=0.5$

$\mathrm{q}=$ Probability of pharmacist with dissatisfaction

$=50 \%=0.5$

$\mathrm{d}=$ margin of error $=0.05$

Sample size $=400$

Questionnaires hard copy were administered personally by coauthor in Kathmandu Valley and by Email or some social networking sites such as viber, whatsap, Imo and Facebook were also used for data collection in some cases for pharmacists practicing outside of Kathmandu valley. In total 600 set of questionnaires were administered by all methods. Ayurvedic and homeopathic pharmacists were excluded.

Ethical approval: Approved from IRC of Manmohan Memorial Institute of Health sciences with IRC register number MMIHS-IRC-297.

Data analysis: Data analysis was done using IBM, SPSS version 16; a statistical software. Satisfaction questions were measured on a 4 point likert scale of satisfaction. Points awarded to the responses were; 1=highly unsatisfied, 2=unsatisfied, $3=$ =satisfied, 4=highly satisfied and all yes/no questions were coded as 1 and 2, Sum, mean, and ratio of different categories were computed and results were analyzed by descriptive statistics. 


\section{RESULTS AND DISCUSSION}

Total 600 sets of questionnaires were administered by different methods. Out of which 416 pharmacists responded. The response rate of the study was $69.33 \%$ where as a study conducted in India the response rate was $32.78 \% 3$. Analysis of responses from 416 pharmacists revealed significant differences in practice scenario and job satisfaction level.

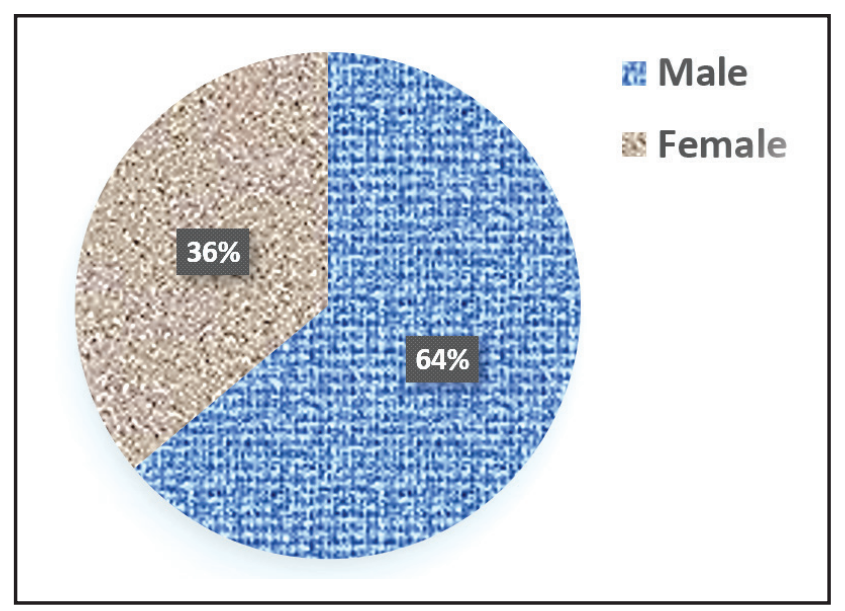

Figure 2: Gender distribution of respondents

$$
(n=416)
$$

The male pharmacists to female pharmacists ratio (fig 2) was $\mathrm{M}=63.94 \% / \mathrm{F}=36.06$. Mean age of working pharmacists (Table I) was 29.29 years and 70\% pharmacists are between ages 20-30 years.

\section{Table 1: Age categories of respondents}

\begin{tabular}{ccc}
\hline Age category & Frequency & Percent (\%) \\
\hline $20-30$ & 292 & 70.20 \\
$30-40$ & 110 & 26.40 \\
$50-60$ & 8 & 1.90 \\
$40-50$ & 4 & 1.0 \\
$>60$ & 2 & 0.5 \\
\hline Total & $\mathbf{4 1 6}$ & $\mathbf{1 0 0}$ \\
\hline
\end{tabular}

A research conducted by Gustafsson $M$ et al [18] reported that the majority of respondents pharmacists were female (95\%), and most were employed at a community pharmacy (85\%). The mean age was 39.7 years. The majority of graduates $(91 \%)$ were satisfied with their job "most of the time" or "all of the time", and $87 \%$ of the respondents would "definitely" or "maybe" choose the same career again.
A study conducted in India [14] reported 300 (79.57\%) respondents were males and 77 (20.42\%) were females. Majority of participants were younger than 30 years $(90.18 \%, n=340)$.

\section{Table 2: Course selection view of respondents}

\begin{tabular}{|c|c|c|}
\hline Join the course & Frequency & Percent (\%) \\
\hline My choice & 281 & 67.50 \\
\hline I got chance to join & 73 & 17.50 \\
\hline Others & 34 & 8.20 \\
\hline $\begin{array}{l}\text { Because my friend } \\
\text { joined the course }\end{array}$ & 15 & 3.60 \\
\hline $\begin{array}{l}\text { Because of my family } \\
\text { pressure }\end{array}$ & 13 & 3.10 \\
\hline Total & 416 & 100 \\
\hline
\end{tabular}

$67.50 \%$ pharmacists had their own choice joining the course, $17.50 \%$ pharmacists admitted to the course by chance (that means they wanted to admitted to medical or dental course, but could not got the opportunity) and rest of them join by family pressure of friend's suggestions etc.

Table 3: University of respondent's graduation

University Name Frequency Percent (\%)

Tribhuvan University

$139 \quad 33.40$

Kathmandu University (KU)

Purbanchal University (PU)

Rajiv Gandhi

University

Pokhara University

40

9.60

Other Universities

47

Total 416
100

In total $88.60 \%$ of the pharmacists were graduated from four Nepalese Universities and Rajiv Gandhi University India, viz: $\mathrm{TU}=33 \%, \mathrm{KU}=23 \%$, PU $12 \%$, Rajeev Gandhi university 11\% and Pokhara university $10 \%$ respectively. 


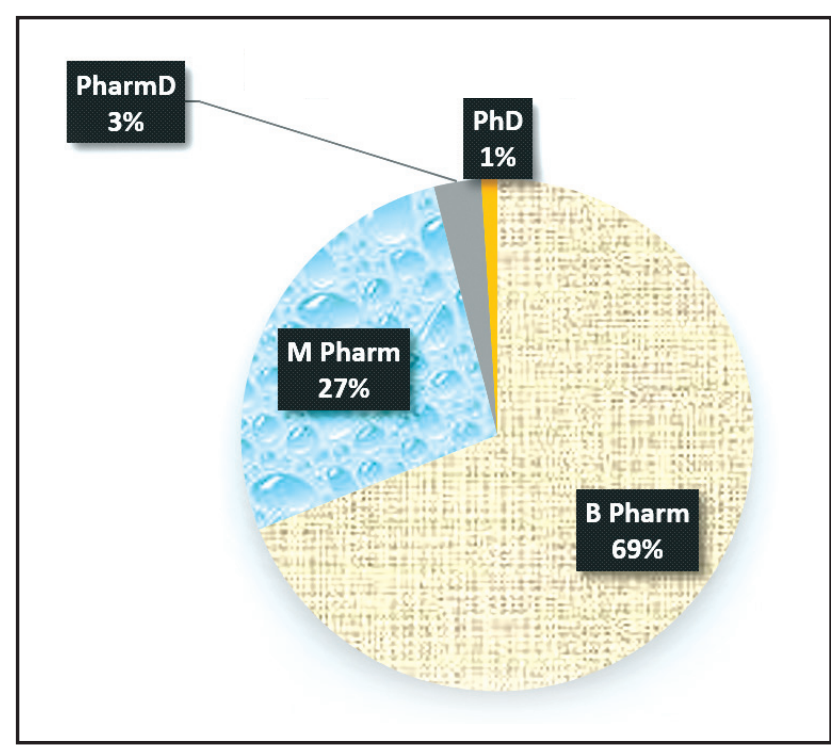

Figure 3: Degrees of respondent pharmacists

$$
(n=416)
$$

Out of 416 respondents (Fig 3), undergraduate (B Pharm or equivalent) were $69 \%$, Graduate (M Pharm or equivalent) 29\%, PharmD 3\% and PhD 1\% respectively. A study done in India14 reported large number of respondents had a qualification of Masters of Pharmacy $(40.58 \%, \mathrm{n}=153)$ followed by Bachelors of Pharmacy (39.78\%, $\mathrm{n}=150)$ ). Hospital pharmacists made a large portion of the sample $(40 \%, \mathrm{n}=151)$. Out of 416 respondents, $24.50 \%$ are working in industry (Table VI), 24\% in hospital, $19.00 \%$ in community, $17.00 \%$ in academia and $16.00 \%$ in regulatory and other sectors respectively. But according to FIP $75 \%$ pharmacists are working in community setting globally1, It is very interesting that equal number (24\%) of practicing pharmacists are working in industries and hospitals (fig: 4). This is the good sign of the development of pharmaceutical service in the hospital sector.

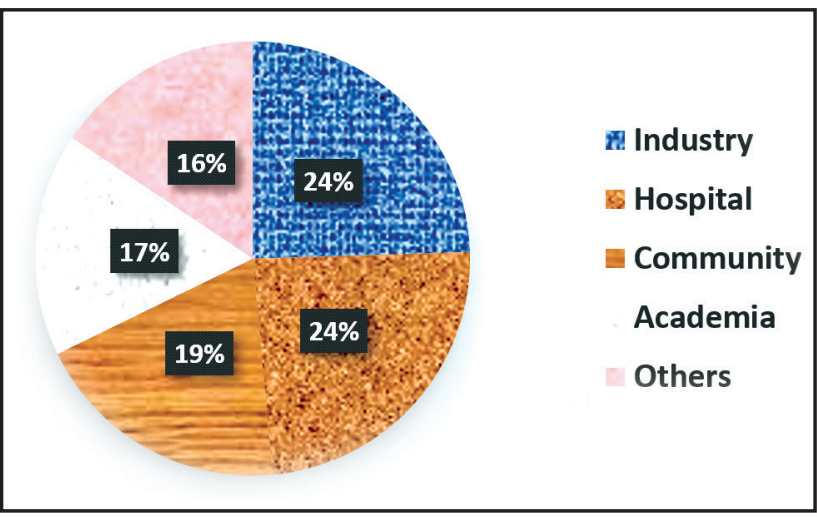

Figure 4: Working sector of respondent pharmacists $(\mathrm{n}=416)$
Table 4: Experience of respondents regarding joining job or remaining jobless after completion of B Pharm course

\begin{tabular}{|c|c|c|}
\hline Jobless & Frequency & Percent (\%) \\
\hline No & 213 & 51.2 \\
\hline Yes ( $<6$ months) & 203 & 48.8 \\
\hline Total & 416 & 100 \\
\hline
\end{tabular}

$51 \%$ join job immediately after graduation and $49 \%$ were jobless for the period of 4-6 months. $26 \%$ of the jobless pharmacists stay as volunteer for 1 month. $38.70 \%$ of practicing pharmacists are working away from the home town (Table VIII), 36.80 at home town, $19.00 \%$ near to home town respectively.

\section{Table 5: Working Place of respondents}

\begin{tabular}{lcc}
\hline \multicolumn{1}{c}{ Working place } & Frequency & Percent (\%) \\
\hline Away from Hometown & 161 & 38.70 \\
Hometown & 153 & 36.80 \\
Near to Hometown & 79 & 19.00 \\
Other & 23 & 5.50 \\
\hline \multicolumn{1}{c}{ Total } & $\mathbf{4 1 6}$ & $\mathbf{1 0 0}$ \\
\hline
\end{tabular}

Expected salary of $43 \%$ of practicing pharmacist is 31-45 thousands NPR (US\$= 278 to 404 in June 2019 exchange rate )/ month, 16\% expect 16-30 thousands NPR (US $\$=144$ to $269 /$ month, where as $10 \%$ expect 46-60 thousands NPR (US\$= 413 to $538 /$ month, 3\% expect above 60 thousands NPR (above US $\$=638 /$ month, and $10 \%$ satisfy in about 15 thousands NPR (UD \$ 140 respectively.

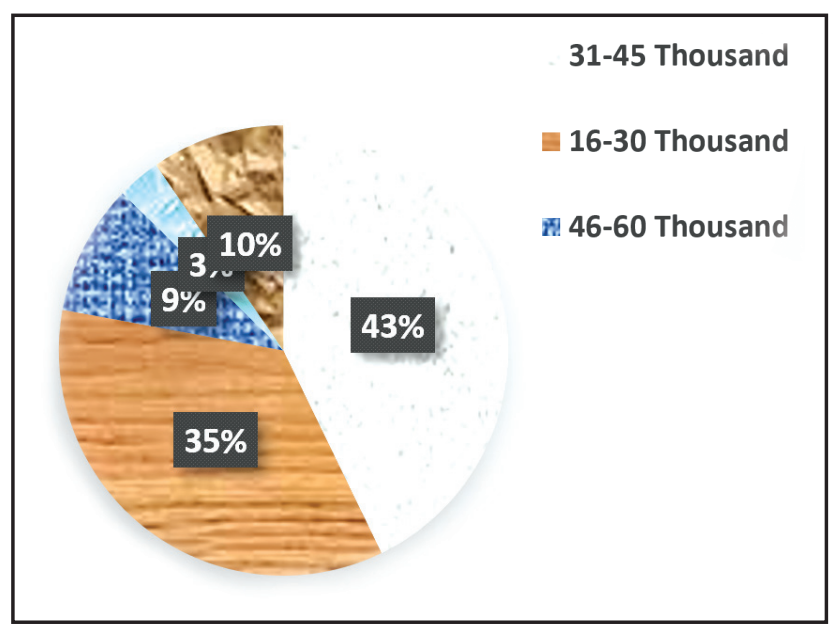

Figure 5: Expected salary of respondent pharmacists $(n=416)$ 
It is very interesting that $35 \%$ practicing pharmacists expect (fig 6) and $50 \%$ of practicing pharmacists are drawing 16-30 thousands NPR ( US\$= 144 to 269 / month, on other hand $43 \%$ practicing pharmacists expect 31-45 thousands NPR (US $\$=278$ to 404 in 2019)/ month but only $28 \%$ are drawing that level of

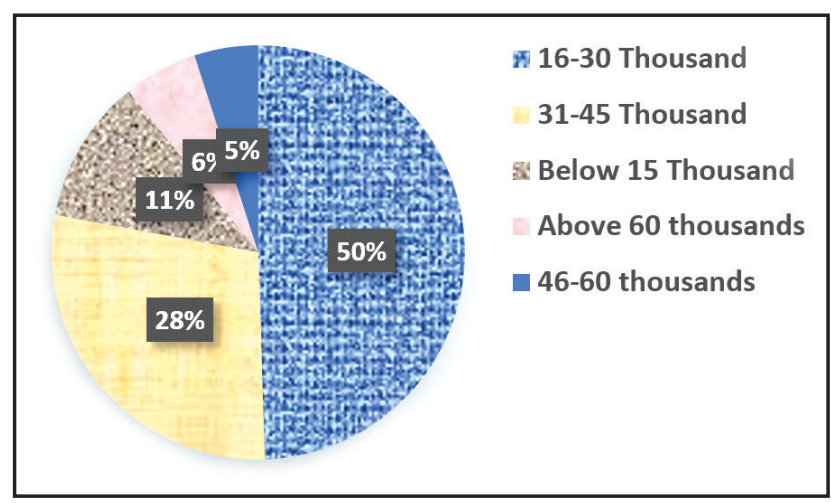

Figure 6: Current salary of respondent pharmacists

$$
(n=416)
$$

Salary presently. In total $10 \%$ expect and $11 \%$ drawing below 15 thousands (UD \$ 140 in 2019/ month) salary. In the upper salary level 9.4\% expect and $5 \%$ of practicing pharmacists are drawing 46-60 thousands NPR (US\$=413 to 538) / month. In the highly paid group $3 \%$ expect above 60 thousands NPR (above US $\$=638 /$ month, but $5.80 \%$ are drawing that level of salary during survey time. In US in 2018, the median pay of a pharmacist was $\$ 126,120$ per year and $\$ 60.64$ per hour ${ }^{10}$.

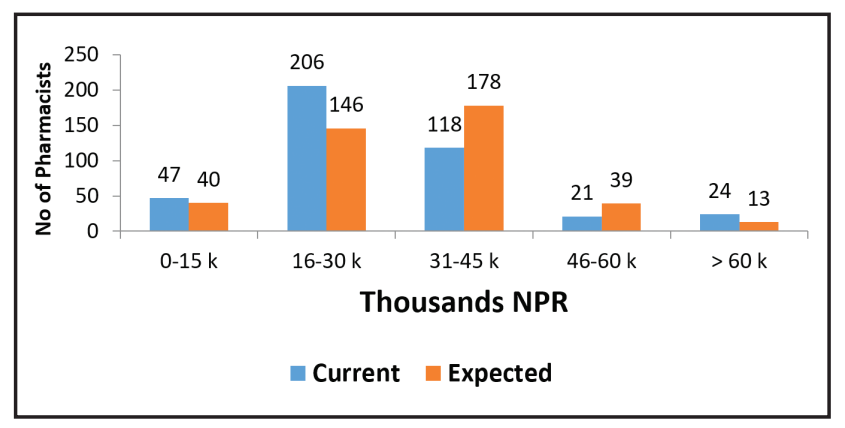

Figure 7: Comparison of current and expected

$$
(n=416)
$$

Figure 8 , shows that $308(74 \%)$ practicing pharmacists were found to be satisfied. Similarly $62(15 \%)$ and 46 (11\%) were found to be highly satisfied and unsatisfied respectively. The findings of other researchers are When asked on a scale of 1 to 7 (with 1 being "not at all" and 7 being "extremely"), how satisfied they are with their current annual total compensation, of 290 pharmacist respondents to that question, about $62 \%$ answered 5,6,or 7. But, when asked how they would rate their current overall job satisfaction on that same scale, of 273 pharmacist respondents to that question, only about $51 \%$ answered 5,6 , or 7 . Some of the top reasons given for their dissatisfaction were workload, management, and work/life balance ${ }^{11}$.

A study conducted in Romania reported a low level of satisfaction regarding the pay-promotion subscale, a high level of satisfaction with the managementinterpersonal relationship dimension, and a high level of satisfaction regarding the organizationcommunication ${ }^{12}$. A research study in India concluded that that the satisfaction level of Indian pharmacists is lower than other countries. Age, qualification and practice setting significantly affected the mean satisfaction score ${ }^{13}$.

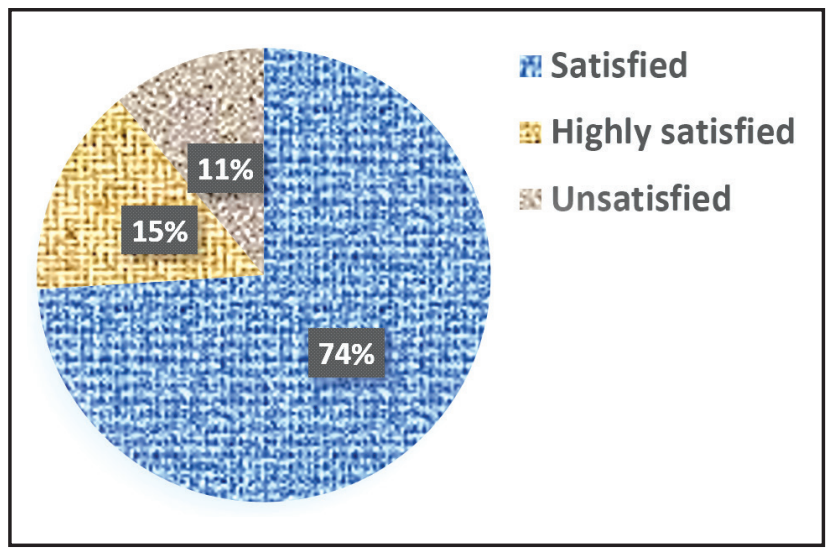

Figure 8: Satisfaction level of practicing pharmacists

A study conducted in Malaysia14 reported that only $52 \%$ of the pharmacists who responded were satisfied with their current jobs. The study outcomes indicate the major factors that affect pharmacists' job satisfaction. A research done in Ethiopia reported that out of 43 total respondents most $32(74.4 \%)$ were satisfied by their job and the rest $11(25.6 \%)$ are not satisfied by their job15. A research conducted in Saudi Arabia, reported that independent community pharmacists in Riyadh had lower levels of job satisfaction than their counterparts in dispensaries and chain pharmacies and similar results reported from the Sweden 16-18. 


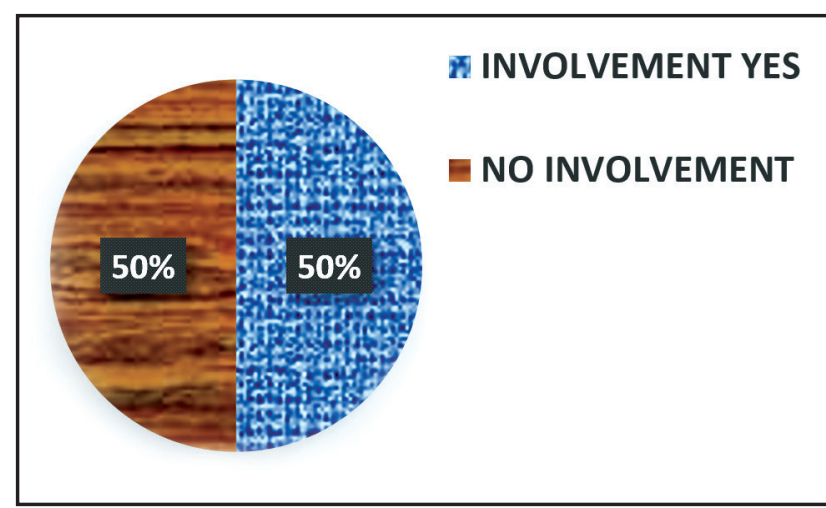

Figure 9: Respondent's involvement in professional pharmacy organizations $(n=416)$

It is very difficult to understand that $50 \%$ of practicing pharmacists are not involved in any professional organizations.

\section{CONCLUSION}

It is interesting that previously industry was the main job hub of pharmacists in Nepal but now hospital sector is also emerging and in present study it is equal to industry. The Government and other authorities have to consider for a universal, multifaceted measure of satisfaction not merely the salary benefits.

\section{REFERENCES}

1. International Pharmaceutical Federation, Hague N. Pharmacy at a Glance. Available from: https://www.fip.org/files/fip/publications/201709-Pharmacy_at_a_Glance-2015-2017.pdf

2. 2009 FIP Global Pharmacy. Fed Int Pharm [Internet]. 2009; Available from: https://fip. org/files/fip/publications/2009_FIP_Global_ Pharmacy_Workforce_Report.pdf

3. Kiron.S.S, Premaletha.K, P.L.Rajagopal, Saritha M. A study on the job satisfaction levels of Pharmacists working in a community pharmacy set-up at northern part of Kerala. IOSR J Pharm [Internet]. 2012;2(3):485-90. Available from: http://iosrphr.org/papers/v2i3/ X023485490.pdf

4. Hardigan P, Carvajal M. Job satisfaction among practicing pharmacists: a Rasch analysis. Internet J Allied Heal Sci Pract [Internet]. 2007;5(4):1-9. Available from: http://ijahsp. nova.edu/ articles/vol5num4/pdf/hardigan.pdf

5. Saul McLeod. Maslow's Hierarchy of
Needs. 2018; Available from: https://www. simplypsychology.org /maslow.html

6. JeromeN.Application of the Maslow's hierarchy of need theory; impacts and implications on organizational culture, human resource and employee's performance. Int J Bus Manag Invent [Internet]. 2013;2(3):39-45. Available from: https://pdfs.semanticscholar.org/b0bc/ c8ca45193eaf700350a8ac2ddfc09a093be8.pdf

7. Seston E, Hassell K, Ferguson J, Hann M. Exploring the relationship between pharmacists' job satisfaction, intention to quit the profession, and actual quitting. Res Soc Adm Pharm. 2009 Jun;5(2):121-32.

8. Khanal DP. History of Pharmaceutical Development in Nepal. J Manmohan Meml Inst Heal Sci. 2018 Feb 9;3(1):86-93.

9. Nepal Pharmacy Council. Pharmacy at a Glance [Internet]. Available from: http://www. nepal pharmacycouncil.org.np/ welcome-tonepal-pharmacy-council/

10. Pharmacist Salary Information | US News Best Jobs [Internet]. [cited 2019 Nov 30]. Available from: https://money.usnews.com/careers/bestjobs/pharmacist/salary

11. Pharmacists : Occupational Outlook Handbook: : U.S. Bureau of Labor Statistics [Internet]. [cited 2019 Nov 30]. Available from: https://www.bls.gov/ooh/healthcare/ pharmacists.htm

12. Pharmacists Are Happy With Their Salaries, Less So With Their Jobs, Survey Shows (Part 1) [Internet]. [cited 2019 Nov 30]. Available from: https://www.pharmacytimes.com/news/ pharmacists-are-happy-with-their-salariesless-so-with-their-jobs-survey-shows-part-1

13. Iorga $\mathrm{M}$, Dondaș $\mathrm{C}$, Soponaru $\mathrm{C}$, Antofie I. Determinants of Hospital Pharmacists' Job Satisfaction in Romanian Hospitals. Pharmacy. 2017 Dec 11;5(4):66.

14. Ahmad A, Khan MU, Elkalmi RM, Jamshed SQ, Nagappa AN, Patel I, et al. Job satisfaction among Indian pharmacists: An exploration of affecting variables and suggestions for improvement in pharmacist role. Indian $\mathrm{J}$ Pharm Educ Res. 2016;50(1):9-16. 
15. Teong WW, Ng YK, Paraidathathu T, Chong WW. Job satisfaction and stress levels among community pharmacists in Malaysia. J Pharm Pract Res [Internet]. 2019 Feb [cited 2019 Nov 30];49(1):9-17. Available from: http://doi. wiley.com/10.1002/jppr.1444

16. Mengesha M, Tigabu BM. Job satisfaction of pharmacists in Ethiopia: The case of Harar town. Int J Pharm Pharm Sci. 2014;6(9):44952.

17. Suleiman A. Stress and job satisfaction among pharmacists in Riyadh, Saudi Arabia. Saudi J Med Med Sci. 2015;3(3):213-9.
18. Gustafsson M, Mattsson S, Wallman A, Gallego G. Pharmacists' satisfaction with their work: Analysis of an alumni survey. Res Soc Adm Pharm. 2018 Jul 1;14(7):700-4.

19. Rai P, Sindan N, Acharya B, Shah R, Shrestha S. Adolescent pregnancy and its outcome in rural teaching hospital, Karnali Academy of Health Science Jumla. JKAHS [Internet]. 30Jul.2019 [cited 11Dec.2019];2(2). Available from: https://jkahs.org.np/jkahs/index.php/ jkahs/article/view/73 